\title{
Size Effects on Surface Generation in Micro Milling Hardened Tool Steel
}

\author{
Bissacco, Giuliano; Hansen, Hans Nørgaard; De Chiffre, Leonardo
}

Published in:

C I R P Annals

Publication date:

2006

Document Version

Publisher's PDF, also known as Version of record

Link back to DTU Orbit

Citation (APA):

Bissacco, G., Hansen, H. N., \& De Chiffre, L. (2006). Size Effects on Surface Generation in Micro Milling Hardened Tool Steel. C I R P Annals, 55(1), 593-596.

\section{General rights}

Copyright and moral rights for the publications made accessible in the public portal are retained by the authors and/or other copyright owners and it is a condition of accessing publications that users recognise and abide by the legal requirements associated with these rights.

- Users may download and print one copy of any publication from the public portal for the purpose of private study or research.

- You may not further distribute the material or use it for any profit-making activity or commercial gain

- You may freely distribute the URL identifying the publication in the public portal

If you believe that this document breaches copyright please contact us providing details, and we will remove access to the work immediately and investigate your claim. 


\title{
Size Effects on Surface Generation in Micro Milling of Hardened Tool Steel
}

\author{
G. Bissacco, H.N. Hansen (2), L. De Chiffre (1) \\ Department of Manufacturing Engineering and Management \\ Technical University of Denmark, Lyngby, Denmark
}

\begin{abstract}
This paper presents the results of an extensive experimental investigation concerning size effects on surface generation by ball nose and flat end micro milling hardened tool steel. Cutting parameters were selected on the basis of a modular description of the uncut chip geometry. A theoretical model of the generated surfaces was used as a reference and compared with measurement results and visual inspection using an SEM. Two main effects have been observed on the tool-work material interaction at micro scale. These are responsible for the limited reduction of the roughness amplitude parameters with tool diameter and occur when the cutting edge radius to uncut chip thickness ratio becomes critical.
\end{abstract}

Keywords:

Micromachining; Milling; Surface.

\section{INTRODUCTION}

The ever increasing need to manufacture small/micro components and features in different materials has led to the development of new technologies. When compared to other micro structuring technologies, the downscaling of the cutting processes presents advantages in terms of freedom of geometry and material removal rate with the disadvantage of a limited miniaturization [1], [2]. The downscaling of the conventional milling process, involving the use of tools with diameters in the sub-millimetre range is commonly referred to as micro milling. Micro milling allows the generation of microstructures characterized by high aspect ratios and complex geometries and is therefore considered as a key technology to manufacture tools for the mass production of micro components like micro moulds for micro injection moulding. In this respect micro milling can be used for the machining of steel in its hardened state, achieving a mould durability comparable to that of conventional size moulds. An overview of the issues related to cutting in hardened steel is reported in [3]. The high workpiece hardness constitutes a major challenge for the process. In fact, the allowable values of depth of cut are as small as $5 \mu \mathrm{m}$ for a $200 \mu \mathrm{m}$ end mill, which implies that machine tool thermal deformations must be compensated in order to avoid premature tool breakage. Besides the realization of the parts, the quality of the generated surfaces is often very important for the functionality. The altered tool-workpiece material interaction, as compared to the process at macro scale, is decisive for the characteristics of surface topography.

This paper presents the results of an analysis of surfaces generated by ball nose and flat end micro milling on hardened tool steel, highlighting and explaining size effects in the generation of surface topography. The work reported here is extracted from [4].

\section{QUANTIFICATION OF SIZE EFFECTS}

\subsection{Features of ideal milled surfaces}

In Figure 1(a) a 3D view of an ideal ball nose end milled surface is shown. The parallel passes in the $Y$ direction are shifted from each other by a distance equal to the step over. The parallel paths generate the high ridges aligned with the $Y$ axis. Cutter marks, almost aligned with the $X$ axis are present between two neighbouring ridges, at regular intervals corresponding to the feed per tooth. The surface is basically constituted by a series of spherical caps of length equal to the step over value and width equal to the feed per tooth. Figure $1 \mathrm{~b}$ shows an ideal flat end milled surface. The cutter marks are aligned with the $X$ direction and spaced of a distance equal to the feed per tooth. When the actual surface is generated by means of multiple parallel passes along the $Y$ direction, the cutter marks generated in one pass can be shifted along $\mathrm{Y}$ relative to those generated in a previous pass. An ideal flat end milled surface appears as constituted by a series of cylindrical caps, with length equal to the axial step depth and width equal to the feed per tooth.

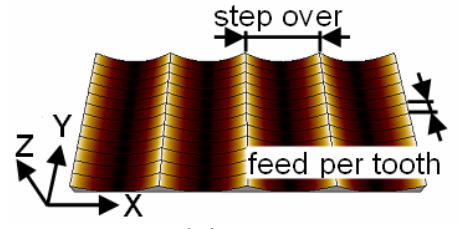

(a)

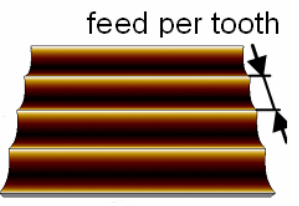

(b)
Figure 1: Surface generated by (a) ball nose and (b) flat end milling.

\subsection{Quantification}

The main objectives in the investigation of size effects are to identify the size limit, where the process behaviour starts to differ from that at macro scale, to explain such departure and to set the basis for effective prediction of the process performance at micro scale. Such results can only be achieved if a reference model, which explains the process at macro scale, is available and a scaled experimental investigation is carried out, in order to allow a comparison between predicted and experimental results.

\subsection{Reference models}

Two analytical models, one for ball nose end milling and 
one for flat end milling, have been developed to be used as reference models. The models simulate the surface based on the simplified ideal kinematical motion but do not take into account the effects of the mechanical interaction between cutting edge and workpiece material, as deflections, vibrations, material deformation. The simulated surfaces can be processed using the software SPIP [5] to calculate roughness parameters.

A major problem for the flat end milling model was that when milling a surface by means of parallel passes, the machine tool repeatability error in the direction orthogonal to the machined surface generates features that greatly increase the surface roughness. This contribution to the surface topography is not taken into account by the model.

In order to validate the models, two sets of three specimens each, in hardened tool steel, were machined. The two series of machined surfaces were measured with a laser profilometer. The results are reported in Table 1. For ball nose end milling the model's error is below $5 \%$, which allows its use as a macro scale reference. For flat end milling the effect of the machine tool repeatability error is responsible for a difference between measured and predicted values of more than $80 \%$. Therefore this second model could not be used as a reference. Details concerning the formulation and validation of the models can be found in [4].

\begin{tabular}{|c|c|c|c|c|c|}
\hline & Parameter & Unit & $\begin{array}{c}\text { Milled } \\
\text { surfaces }\end{array}$ & $\begin{array}{c}\text { Model } \\
\text { predictions }\end{array}$ & $\begin{array}{c}\% \\
\text { difference }\end{array}$ \\
\hline \multirow{2}{*}{$\begin{array}{l}\overline{\bar{\sigma}} \\
\overline{\mathscr{D}} \\
\infty\end{array}$} & $S q$ & $\mu \mathrm{m}$ & 1.09 & 1.12 & 2.8 \\
\hline & Scd5_95 & $\mu \mathrm{m}$ & 3.55 & 3.39 & -4.5 \\
\hline \multirow{2}{*}{ 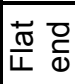 } & $\mathrm{Sq}$ & $\mu \mathrm{m}$ & 0.71 & 0.10 & -85.9 \\
\hline & Sdc5_95 & $\mu \mathrm{m}$ & 2.34 & 0.31 & -86.7 \\
\hline
\end{tabular}

Table 1: Roughness parameters of machined and simulated surfaces. Ball end milling: radius $3 \mathrm{~mm}$, feed per tooth $48 \mu \mathrm{m}$, step over $300 \mu \mathrm{m}$, surface angle $70^{\circ}$.

Flat end milling: diameter $6 \mathrm{~mm}$, feed per tooth $90 \mu \mathrm{m}$,

$$
\text { step depth } 300 \mu \mathrm{m} \text {. }
$$

\subsection{Scaled experimental investigation}

For the selection of the cutting parameters a geometrical downscaling or modular approach was used. With this solution all the cutting parameters are scaled according to the tool diameter. The determination of the cutting parameters is made through the definition of appropriate values for the modular parameters, which are the cutting parameters divided by the tool diameter. The main consequence is that the uncut chip shape is made independent of the absolute dimension of the process, which is determined by the tool diameter only. It also implies that, if no size effects are present, the deformation pattern of the removed material remains ideally the same, regardless of the tool diameter.

\section{Ball nose end milling tests}

The scaled investigation was based on a full factorial four factors experimental design. In accordance with the modular approach, the selected variables were the tool diameter $D$, the modular feed per tooth $a_{z} / D$, the cutting speed $V$ and the surface inclination angle $\alpha$. The modular step over $a_{t} / D$ and the modular depth of cut $a_{r} / D$ were kept at constant values. The tool diameter was varied in four levels, in the range from $6 \mathrm{~mm}$ to $200 \mu \mathrm{m}$, thereby including conventional size as well as micro end mills. The modular feed per tooth, the cutting speed and the surface inclination angle were varied in three levels. The maximum value of the cutting speed was limited to 30 $\mathrm{m} / \mathrm{min}$ as a result of the combination of the maximum rotational speed available and the minimum tool diameter.

\section{Side end milling tests}

The scaled investigation was based on a full factorial three factors experimental design. In accordance with the modular approach, the selected variables were the tool diameter $D$, the modular feed per tooth $a_{z} / D$ and the cutting speed $V$. The modular radial depth of cut $a_{e} / D$ and the modular axial depth of cut $a_{p} / D$ were kept at constant values.

The two sets of experiments were carried out in down milling mode and the selected parameter values are reported in Table 2.

\begin{tabular}{|l|l|c|}
\hline Parameter & \multicolumn{1}{|c|}{ Ball nose } & \multicolumn{1}{|c|}{ Flat end } \\
\hline Diameter D [mm] & $6 ; 1 ; 0.6 ; 0.2$ & $6 ; 1 ; 0.6$ \\
\hline Modular feed per tooth $\mathrm{a}_{\mathrm{z}} / \mathrm{D}$ & $\begin{array}{l}0.002 ; 0.005 ; \\
0.008\end{array}$ & $\begin{array}{l}0.005 ; 0.01 ; \\
0.015\end{array}$ \\
\hline Modular step over $\mathrm{a}_{\mathrm{f}} / \mathrm{D}$ & 0.05 & --- \\
\hline $\begin{array}{l}\text { Modular radial depth of cut } \\
\mathrm{a}_{\mathrm{e}} / \mathrm{D}\end{array}$ & \multicolumn{1}{|c|}{---} & 0.05 \\
\hline Modular depth of cut $\mathrm{a}_{\mathrm{r}} / \mathrm{D}$ & $0.05^{*}$ & \multicolumn{1}{|c|}{--} \\
\hline $\begin{array}{l}\text { Modular axial depth of cut } \\
\mathrm{a}_{\mathrm{p}} / \mathrm{D}\end{array}$ & \multicolumn{1}{|c|}{--} & 0.05 \\
\hline Cutting speed V [m/min] & $10 ; 20 ; 30$ & $10 ; 20 ; 30$ \\
\hline Surface angle $\alpha$ [deg] & $0 ; 10 ; 70$ & --- \\
\hline
\end{tabular}

Table 2. Cutting parameters in ball nose and flat end milling. * reduced to 0.025 for the $200 \mu \mathrm{m}$ ball end mills.

\section{EXPERIMENTAL}

\subsection{Experimental set up for cutting tests}

The machine tool used was a 3 axis CNC vertical milling machine equipped with a high speed attached spindle having a maximum rotational speed of $50000 \mathrm{rpm}$ and run out within $1 \mu \mathrm{m}$. The working environment was a precision mechanics workshop provided with air conditioning for temperature control $\left(21^{\circ} \mathrm{C} \pm 2^{\circ} \mathrm{C}\right)$. High accuracy control of the axial depth of cut was achieved through compensation for machine tool thermal deformations as described in [6]. The experiments were carried out on a powder metallurgy martensitic stainless steel, with a hardness of $58 \mathrm{HRC}$. The average grain size was measured to be $5 \mu \mathrm{m}$. Such a small grain size was desired to reduce the grain size to chip thickness ratio size effects, achieving a more favourable combination. Moreover, hard and homogeneous material states are a prerequisite for micro cutting of steel with tungsten carbide tools, when minimization of burrs and good surface quality are desired [7]. The tools used were twofluted, long neck type, PVD coated, ball nose and flat end mills. A $5 \%$ oil emulsion was used as cutting fluid. The relatively low stiffness of the long neck tools was beneficial in minimizing the effects of tool run out on the surface topography, as the elastic deformation of the tool, proportional to the radial cutting force, reduces the unbalance of contact length and chip thickness between the two flutes. No chatter was detected during the tests.

\subsection{Measuring instruments and methods}

The machined surfaces were measured using a focus detection laser profilometer. Although absolute values of roughness amplitude parameters are generally overestimated by the focus detection laser profilometer, its use proved to be reliable for a comparative analysis of machined surfaces [8]. The verification of the tendencies detected on the basis of laser profilometer measurements were verified through a series of measurements performed on selected surfaces by means of an AFM and a 3D contact profilometer. Because parameters are inherently synthetic and cannot completely describe the complex reality of a surface [9], the combination of these 
instruments with SEM images of the machined surfaces allowed a complete characterization of the topography obtained with the processes considered. The image files generated were plane corrected (first order polynomial) and filtered using a 3D Gaussian filter with appropriate short and long cut-off wavelengths [4]. The calculation of roughness parameters was performed on the filtered surfaces using the image processing software SPIP [5]

\subsection{Surface texture parameters}

The 3D surface texture parameters selected were $\mathrm{Sq}$ and Sdc_5-95. The latter represents the height difference between the planes, parallel to the filtered surface, at $5 \%$ and $95 \%$ bearing area ratio. Sdc 5-95 is used here as an alternative to the parameter $\mathrm{Sz}$, since it is more robust than Sz, particularly when using instruments based on focus detection. It is also more comparable with the $\mathrm{Rz}$ values from $2 \mathrm{D}$ profile measurements. A detailed discussion about the advantages of using Sdc_5-95 can be found in [4].

\section{EVALUATION OF EXPERIMENTAL RESULTS}

\subsection{Statistical analysis and empirical models}

Multivariate ANOVA was performed in order to discern the process parameters that significantly influence the selected roughness amplitude parameters. Based on the ANOVA results, empirical models have been derived for Sq and Sdc_5-95 and for the two types of surfaces.

\section{Ball nose end milling}

For both Sq and Sdc_5-95, and in the range of process parameters considered here, only tool diameter and surface angle were found to affect significantly the generated surfaces. In both cases, nonlinear empirical models were derived (Table 3 ). The model functions and fitted data reported in Figure 2 show a very steep increase of the Sq and Sdc 5-95 values at $\alpha$ close to $0^{\circ}$. This is in contrast with [10], where a linear dependency of Ra on surface inclination angle, from $0^{\circ}$ to $60^{\circ}$, is reported for high speed ball nose end milling with $6 \mathrm{~mm}$ end mills.

\section{Flat end milling}

Only the tool diameter $D$ and the two terms interactions of the modular feed per tooth with both tool diameter and cutting speed generated statistically different groups. However, the contribution due to the tool diameter alone is almost negligible in the range considered. The models' equations are reported in Table 3.

\subsection{Tool size dependent amplitude parameters}

\section{Ball nose end milling}

Due to the insensitivity of the simplified theoretical model to the surface inclination angle, comparisons between the theoretical and empirical models are possible only at constant surface angle. Such comparison is shown in Figure 3 for Sq and Sdc_5-95. The diagrams show that theoretical models and empirical models are in good accordance with the experimental data for a diameter of 6 $\mathrm{mm}$ at $10^{\circ}$ and $70^{\circ}$. The empirical models are linear with respect to the variable diameter, but with different slopes than the theoretical model. Moreover the intercept at $D=0$ is not null. Thus, while the theoretical model predicts a perfect scalability of surface roughness amplitude parameters, the empirical models show that size reduction in the ball nose end milling process, maintaining constant modular parameters, produces increasing relative amplitude parameters. This is an analytical evidence of the occurrence of size effects in surface generation by ball nose micro milling. From the comparison of Figure 3 with the data in Table 4 it is possible to verify that the reduction of Sq and Sdc_5-95 with tool diameter is limited by the reduced efficiency of the cutting action for low tool diameters. This occurs when the average uncut chip thickness is less than or equal to the cutting edge radius, which, for the smallest tools used here, showed local values of $1-4 \mu \mathrm{m}$.

\section{Flat end milling}

Although the model could not be used as a reference, the constant terms in the equations in Table 3 express the fact that the topography of flat end milled surfaces does not show perfect scalability.

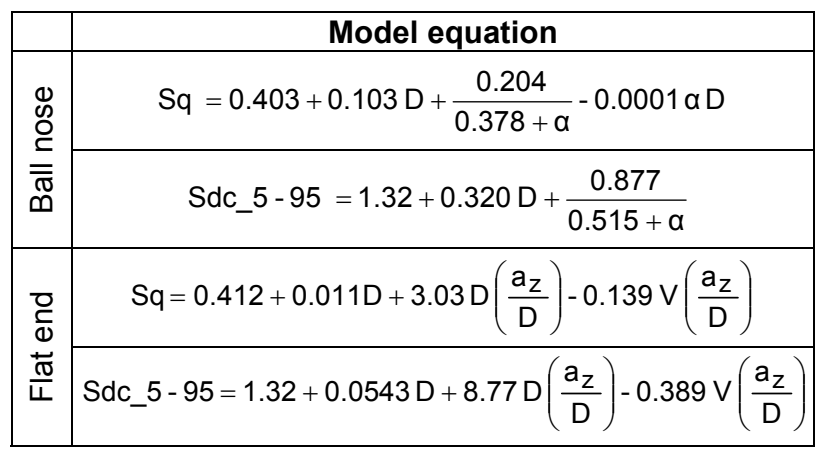

Table 3: Empirical models for Sq and Sdc_5-95 of ball and flat end milled surfaces.
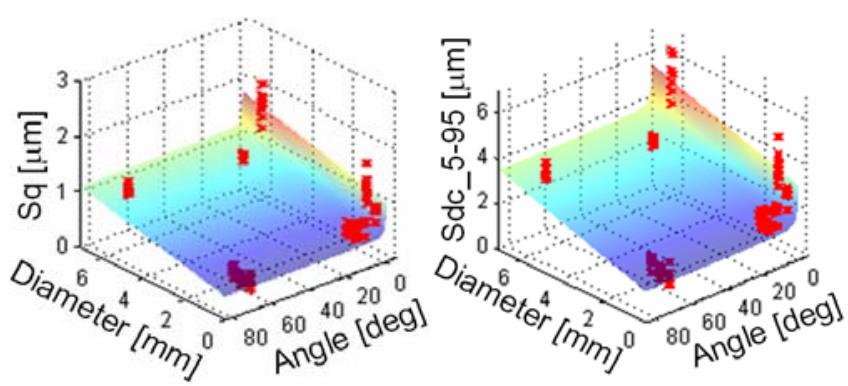

Figure 2: Sq and Sdc_5-95 model functions.
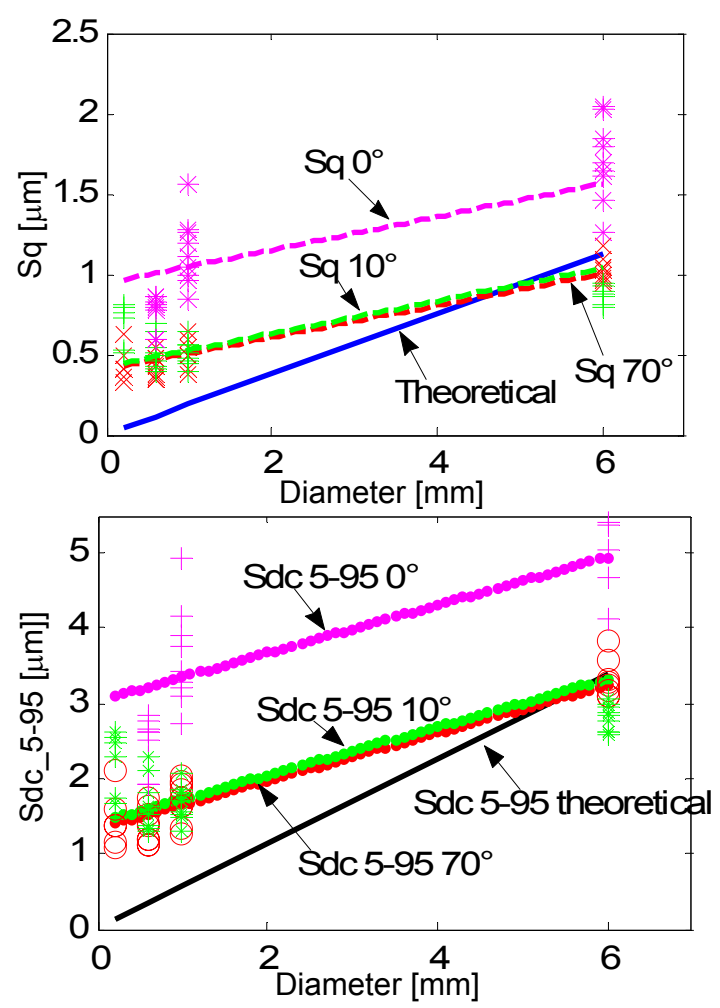

Figure 3: Sq and Sdc_5-95 as a function of tool diameter according to empirical and theoretical models. 


\begin{tabular}{|c|c|c|c|}
\hline \multirow{2}{*}{$\mathbf{D}[\mathbf{m m}]$} & \multicolumn{3}{|c|}{ Max uncut chip thickness $[\boldsymbol{\mu m} \mathbf{m}]$} \\
& $\mathbf{0}^{\circ}$ & $\mathbf{1 0}^{\circ}$ & $\mathbf{7 0}^{\circ}$ \\
\hline 0.2 & -- & $0.12-0.47$ & $0.17-0.70$ \\
0.6 & $0.33-1.33$ & $0.39-1.57$ & $0.52-2.08$ \\
1 & $0.56-2.22$ & $0.65-2.62$ & $0.87-3.47$ \\
6 & $3.33-13.33$ & $3.93-15.71$ & $5.20-20.81$ \\
\hline
\end{tabular}

Table 4: Maximum uncut chip thickness in ball nose end milling tests. Values refer to range of feed per tooth.

\section{TOOL-WORKPIECE INTERACTION AT MICROSCALE}

In order to provide an explanation for the non scalability of the surface roughness, observation of the micro milled surfaces was carried out by means of SEM images and $3 D$ plots of AFM scans. By contrast to the "clean cutting" obtained in conventional size milling, in micro milling the effects of a less efficient cutting action are apparent. In ball nose micro milling, the ridges are comparatively higher than in conventional size milling and smeared material, still attached to the surface is projected in the direction opposite to the pick feed. This is clearly visible in Figure $4 a$, which shows an SEM image of a surface machined with a $0.2 \mathrm{~mm}$ ball nose end mill at $70^{\circ}$. The accumulation of smeared material on the main ridges is observed at all inclination angles with tool diameters of $0.2 \mathrm{~mm}$ and $0.6 \mathrm{~mm}$. This is believed to occur at the beginning of the engagement of the cutting edge with the work material, at each tooth passing. When the cutting edge is entering the cut, due to the large edge radius relative to the local uncut chip thickness, the ratio between the thrust force and the cutting force becomes very high. Some material is then pushed aside, where the deformation is made easier because of the missing material, removed in the previous pass. A second feature characteristic of ball nose micro milled surfaces is the material smeared behind the tool as shown in Figure $4 \mathrm{~b}$. Such material appears as small waves along the feed direction and oriented opposite to the feed. The formation of such waves is a dominant effect at low surface inclination angles $\left(0^{\circ}\right.$ and $\left.10^{\circ}\right)$ and is believed to occur at the end of the engagement arc, at each tooth passing. The waves are made of material plastically deformed and belonging to the last part of the chip. In fact, in down milling, the chip thickness approaches zero in the last part of the engagement arc, and the actual rake angle becomes highly negative due to the presence of the edge radius. In these conditions it is likely that the chip is broken at a certain point of the engagement arc and the material belonging to the remaining part of the ideal chip geometry is deformed by the cutting edge in an ironing like operation. A similar effect is visible on the flat end milled surfaces, where the unfavourable ratio between chip thickness and cutting edge radius results in the formation of waves of plastically deformed material in the feed direction. This is shown in Figure 5. In Figure 4 and 5 no effect of tool run out or chatter are visible. This confirms the statements in paragraph 3.1.

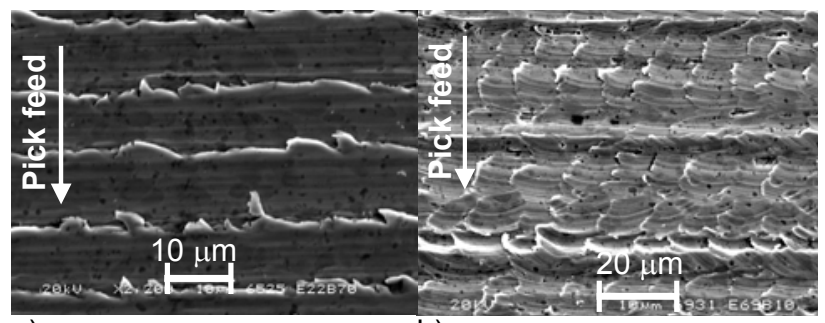

a)

$$
\text { b) }
$$

Figure 4: Surfaces generated by ball nose micro milling:

a) tool diameter $0.2 \mathrm{~mm}$, surface angle $70^{\circ}$; b) tool diameter $0.6 \mathrm{~mm}$, surface angle $10^{\circ}$.

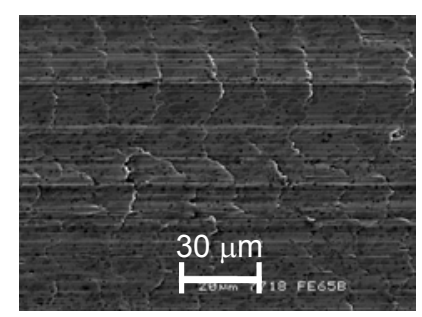

Figure 5: Surface milled with a $0.6 \mathrm{~mm}$ flat end mill.

\section{CONCLUSIONS}

The results of an analysis of the surfaces generated within an experimental investigation have been presented, highlighting and explaining size effects in the generation of surface topography in micro milling of hardened tool steel. Besides the quantitative verification of the non perfect scalability of the surface roughness, obtained through the evaluation of the amplitude parameters $\mathrm{Sq}$ and Sdc_5-95, two effects of the increased ratio between cutting edge radius and chip thickness have been observed on the tool - work material interaction at micro scale. The first one is strictly related to the geometry of the tool and consists in the accumulation of plastically deformed material in the main ridges of the machined surface. The second one consists in the smearing of material behind the tool, forming small waves in the feed direction. These two effects are responsible for the limited reduction of the roughness amplitude parameters with tool diameter.

\section{REFERENCES}

[1] Alting L., Kimura F., Hansen H. N., Bissacco G. 2003, Micro Engineering, Annals of the CIRP, 52/2:635-657.

[2] Masuzawa, T., 2000, State of the art of micromachining, Annals of the CIRP, 49/2:473488.

[3] Tönshoff H. K., Arendt C., Ben Amor R., 2000, Cutting on Hardened Steel, Annals of the CIRP, 49/2:547-566.

[4] Bissacco G., 2004, Surface Generation and Optimization in Micromilling, Ph.D. Thesis, Technical University of Denmark.

[5] SPIP TM The Scanning Probe Image Processor, Image Metrology A/S, www.imagemet.com.

[6] Bissacco G., Hansen H. N., De Chiffre L., 2005, Investigation on a procedure for optimal axial depth of cut accuracy in micromilling, Proc. 5th Euspen Int. Conf., Montpellier, France, p. 557560.

[7] Weule H., et al., 2001, Micro-Cutting of Steel to Meet New Requirements in Miniaturization, Annals of the CIRP, 50/1: 61-64.

[8] Bariani P. , Bissacco G., Hansen H. N., De Chiffre L., 2004, Experimental characterization of micromilled surfaces by large range AFM, Proc. Nanoscale Int. Seminar, Braunschweig, Germany.

[9] De Chiffre L., Lonardo P., Trumphold H., Lucca D. A., Goch G., Brown C. A., Raja J., Hansen H. N., 2000, Quantitative Characterization of Surface Texture, Annals of the CIRP, 49/2:635652.

[10] Axinte D.A., Dewes R.C., Surface integrity of hot work tool steel after high speed milling experimental data and empirical models, 2002, Int. J. Materials Processing Technology, 127, 325-335. 